\title{
Planar Perovskite Solar Cells Using Fullerene C70 as Electron Selective Transport Layer
}

\author{
Fatemeh Jafari Nodoushan $^{\mathrm{a}, \mathrm{b}}$, Abbas Behjat ${ }^{\mathrm{a}, \mathrm{b}, *}$, Naeime Torabi ${ }^{\mathrm{b}}$, Mehrad Ahmadpour ${ }^{\mathrm{c}}$, \\ Bhushan Ramesh Patil ${ }^{\mathrm{c}}$, Vida Turkovic ${ }^{\mathrm{c}}$ and Morten Madsen ${ }^{\mathrm{c}}$ \\ ${ }^{a}$ Physics Department, Yazd University, Yazd, Iran \\ ${ }^{\text {b}}$ Photonics Research Group, Yazd University, Yazd, Iran

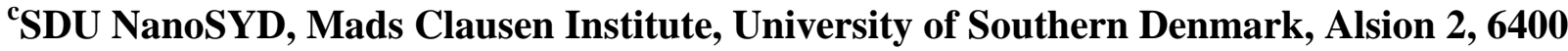 \\ Sønderborg, Denmark
}

*Corresponding Author Email: abehjat@yazd.ac.ir

Regular paper: Received: May. 27, 2019, Revised: Dec. 16, 2019, Accepted: Dec. 23, 2019,

Available Online: June. 30, 2020, DOI: 10.29252/ijop.14.1.15

\begin{abstract}
Owing amongst other to its high electron mobility, fullerene $\mathbf{C 7 0}$, has been widely used as an electron transporting layer in organic solar cells. In this research, we report the use of $\mathrm{C70}$ thin films as electron transport layers of planar perovskite solar cells (PSCs) using a conventional device structure. The thickness of the C70 layer has been optimized to achieve the best efficiency of $12 \%$. It is demonstrated that ultra-thin C70 films can effectively block holes and thus become selective to the transport of electrons in PSC devices.
\end{abstract}

KEYWORDS: Perovskite solar cell, $\mathrm{CH} 3 \mathrm{NH} 3 \mathrm{PbI} 3$, Electron transport layer (ETL), Fullerene, C70, Interface engineering

\section{INTRODUCTION}

Organometallic halide perovskite solar cells (PSCS) have recently attracted significant interest owing to their superior optoelectronic properties, such as long electron-hole diffusion lengths $(>1 \mu \mathrm{m})$ [1], high absorption coefficient, tunable band gaps, high charge carrier mobility and long charge carrier life span (>100 ns) [2-5], which mainly arise due to their specific crystalline structure [6]. The general structure of perovskite absorber materials is $\mathrm{AMX} 3$, where $\mathrm{A}$ is a large cation (typically $\mathrm{CH} 3 \mathrm{NH} 3+$ ), $\mathrm{M}$ is a divalent metal cation (typically $\mathrm{Pb} 2+$ ) and $\mathrm{X}$ is a halogen (typically $\mathrm{Cl}, \mathrm{Br}$ or I ) [7, 8]. Miyasaka et al. presented the first perovskite solar cells in 2009 [9]. They used a liquid electrolyte as a hole transport material, resulting in the power conversion efficiency (PCE) of around 3-4\%. Nowadays, within a relatively short time, the PCE of PSCs has reached around 23.3\% [10] . Most high-efficiency PSCs have a mesoscopic structure, but these structures require hightemperature fabrication processes (up to $500^{\circ} \mathrm{C}$ ), which increases manufacturing costs and limits printable and flexible fabrication $[11,12]$. Recently, planar PSCs based conventional and inverted structures have attracted extensive attention because of their low-temperature processes, simple preparation and flexible manufacturing capacity [13-16]. The electron transport layer (ETL), however, is critical for planar perovskite solar cells. It is usually sandwiched between the perovskite absorber layer and the cathode to aid carrier separation and especially support efficient collection of electrons at the cathode [12]. Fullerenes and their derivatives are good candidates as ETL in planar PSCs. This is due to their relatively high electron mobility and efficient hole-blocking property [7, 17], arising from a low-lying HOMO level. Shao et al. showed that fullerene layers, such as PC61BM ETLs, can effectively passivate charge trap states at $\mathrm{CH} 3 \mathrm{NH} 3 \mathrm{PbI} 3$ perovskite film surfaces and grain boundaries, and from that reduce the hysteresis in perovskite devices 
[18]. C70 is another fullerene derivative that have been utilized heavily in organic solar cell development [19-22] and potentially can be utilized as an efficient ETL in perovskite solar cells. As shown in Fig. 1(b), C70 has a Lowest Unoccupied Molecular Orbital (LUMO) at 4.2 $\mathrm{eV}$ [23], which provides an excellent ETL for CH3NH3PbI3 perovskite absorber-based PSCs with a LUMO level at $3.9 \mathrm{eV}$ [24], although it should be noted that the exact alignment across the interface has not been measured. In addition, the hydrophobic surface of C70 compared to PCBM (water contact angle of 99.6 [25] vs. $86.5^{\circ}$ [26]) can result in enhanced stability of PSCs in ambient atmosphere. This is potentially of high importance due to the multiple different degradation mechanisms that currently impact PSC technology [27, 28]. In this study, we introduce for the first time a C70 thin film deposited (at substrate room temperature) to serve as an electron transport layer for planar perovskite solar cells with a conventional device structure. The significant quenching intensity of the Photoluminescence (PL) measurement showed that a C70 layer can be an excellent electron extraction and efficient hole blocking layer for PSCs. Due to the thickness optimization of $\mathrm{C} 70$ and the high quality of the perovskite layer, the best efficiency of $12 \%$ was obtained for these devices.

\section{EXPERIMENTAL}

\section{A. Materials and device fabrication}

Pre-patterned ITO-coated glass substrates (Kintec Company, Hong Kong) were used for a PSC area of $10 \mathrm{~mm} 2$. The sheet resistance of the ITO was approximately $15 \Omega /$ sq. The substrates were cleaned sequentially in an ultrasonic water bath with a detergent, deionized water, acetone and IPA (10 min for each). Then, they were blow dried with a nitrogen gun. C70 (Sigma-Aldrich) layers with the thicknesses of $X=7.5,10,20,30$ and 40 $\mathrm{nm}$ were deposited at a growth rate of $0.2 \AA / \mathrm{s}$ through Organic Molecular Beam Deposition (OMBD) at a base pressure of $3 \times 10-8$ mbar. A PCBM precursor solution was prepared through dissolving $20 \mathrm{mg}$ PCBM in $1 \mathrm{~mL}$ of
Chlorobenzene (Sigma-Aldrich) and then spincoated at $1500 \mathrm{rpm}$ for 60 seconds. $\mathrm{CH} 3 \mathrm{NH} 3 \mathrm{PbI} 3$ perovskite films were deposited by a one-step method and with antisolvent treatment; $461 \mathrm{mg}$ of PbI2 (Alfa Aesar, 99.99\%), $159 \mathrm{mg}$ of CH3NH3I (SigmaAldrich) and $70.9 \mu \mathrm{l}$ of DMSO (SigmaAldrich) were mixed in $635 \mu \mathrm{l}$ of $\mathrm{N}, \mathrm{N}$ dimethylformamide (DMF) (Sigma-Aldrich) at $70 \mathrm{oC}$. The mixture was stirred for an hour until a completely dissolved solution was obtained. This solution was then spin-coated on the ETL at $4000 \mathrm{rpm}$ for 35 seconds, and $70 \mu \mathrm{l}$ of chlorobenzene was slowly dripped on the rotating substrate in 10 seconds before the surface became turbid due to the rapid vaporization of DMF. The transparent film was heated at $100 \mathrm{oC}$ for three minutes in order to obtain a dense $\mathrm{CH} 3 \mathrm{NH} 3 \mathrm{PbI} 3$ film. For the HTL, a Spiro-OMeTAD precursor solution was prepared through dissolving $72.5 \mathrm{mg}$ of Spiro-OMeTAD (Sigma-Aldrich), 28.5 $\mu \mathrm{L}$ of 4-tert-butylpyridine (Sigma-Aldrich) and 17.5 $\mu \mathrm{L}$ of a lithium bis(trifluoromethanesulfonyl) imide (Sigma-Aldrich) solution $(520 \mathrm{mg} / \mathrm{mL}$ in acetonitrile) in $1 \mathrm{~mL}$ of chlorobenzene. This hole transport solution was spin-coated at 4000 rpm for 30 seconds. Finally, $80 \mathrm{~nm}$ of an $\mathrm{Au}$ electrode layer was deposited by the E-beam evaporation system through a shadow mask.

\section{B. Film and device characterization}

All the characterizations were performed in an ambient environment. The current densityvoltage $(\mathrm{J}-\mathrm{V})$ characteristics of the PSCs were measured using a 2400 source measure unit (Keithley Instruments Inc., USA) and a class AAA solar simulator (Sun 3000, Abet Technologies Inc., USA). The J-V characteristics were measured through applying a voltage sweep from +1.5 to $-0.5 \mathrm{~V}$ under a calibrated lamp intensity of 100 $\mathrm{mW} / \mathrm{cm} 2$. The PL intensity measurements of the structure ITO/C70 $(0$ and 10 $\mathrm{nm}) /$ Perovskite were performed through a microscope objective (Nikon E Plan 50X 0.75 EPL) with a fluorescence microscope (Nikon Eclipse ME600) connected to a Maya2000Pro spectrometer (from Ocean optics). The spectrometer had a mercury short-arc lamp with a filtered excitation wavelength of 330 
$380 \mathrm{~nm}$ serving as a source of light. Finally, the SEM image of the perovskite layer was taken with a scanning cold field emission electron microscope (Hitachi S-4800 SEM).

\section{RESULTS AND DISCUSSION}

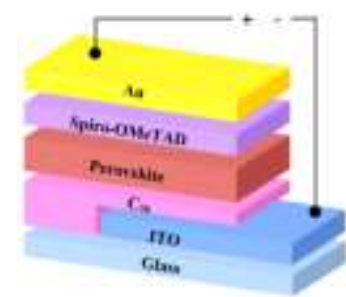

a)

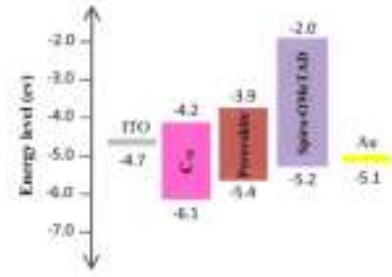

b)
Fig. 1 a) Planar PSC device architecture with C70 as ETL, b) Energy level diagram of PSC with a conventional device configuration.

Figure 1(a) illustrates the device configuration used in this study. The structure of the planar PSC device consists of a compact C70 layer as ETL, a CH3NH3PbI3 perovskite absorber film and a spiro-OMeTAD film as hole transport layer (HTL). Figure 1(b) shows the energy levels of each layer in the device.

To have high-efficiency PSCs, the quality of perovskite films should be given utmost importance. As demonstrated in numerous studies[29], it is challenging to control the formation process of high-quality perovskite films that possess a high surface coverage with no pinholes on planar substrates. Different crystallization strategies, such as antisolvent engineering and fast depositioncrystallization, can affect the crystalline domains, and thus also the performance of the resulting solar cells [29-31]. In this study, a high-quality perovskite film was formed by spin-coating of a solution containing equimolar MAI, PbI2, DMF and DMSO. Also, chlorobenzene was used to remove solvent DMF [32]. As the scanning electron microscopy (SEM) image in Fig. 2 confirms, a high-quality $\mathrm{CH} 3 \mathrm{NH} 3 \mathrm{PbI} 3$ perovskite film was prepared on C70-coated ITO substrates by the one-step solution method using an antisolvent (chlorobenzene) treatment. The figure also shows the dense and smooth surface of the perovskite film with large crystalline grains.

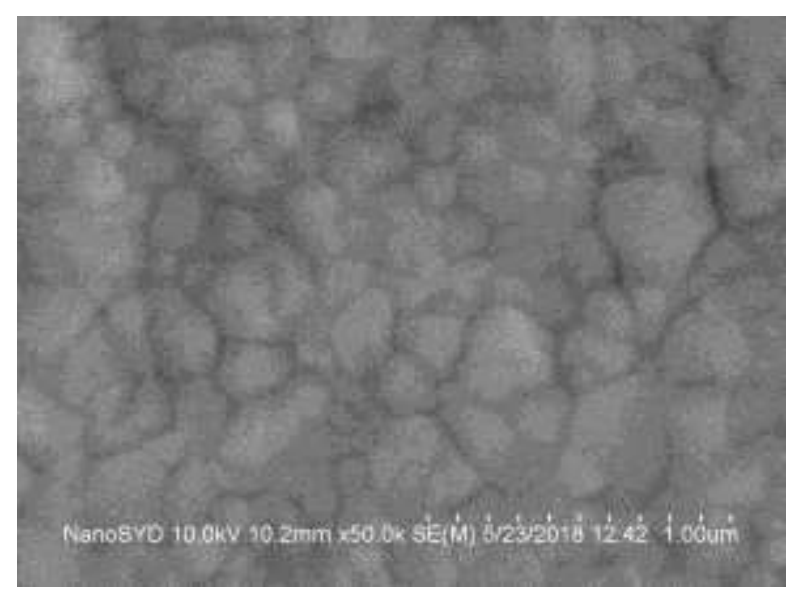

Fig. 2. Top view SEM image of a perovskite film prepared on ITO substrate covered with a $10 \mathrm{~nm}$ C70 film.

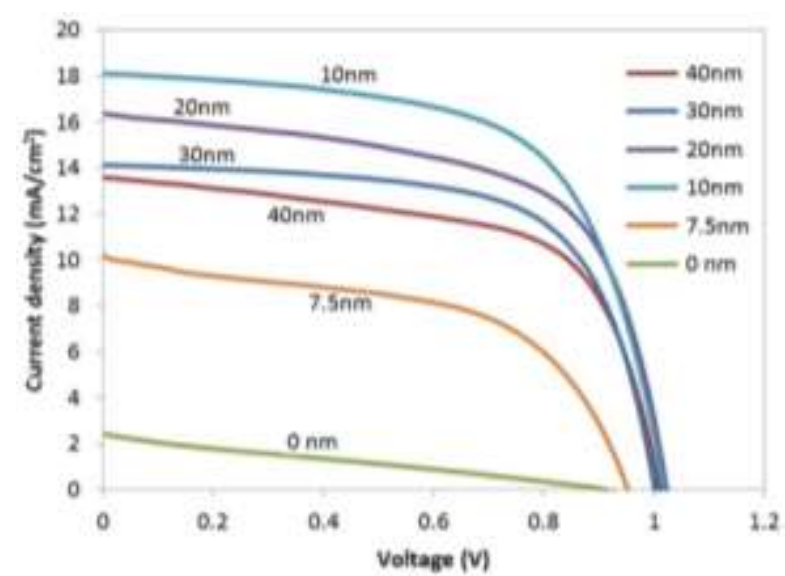

Fig. 3. The JV characteristics of the representative $\mathrm{J}-\mathrm{V}$ curves for the PSC devices with various thicknesses of the C70 layer as ETL.

Due to the limited electron mobility of organic ETLs and the absorption of C70, the thickness of C70 films in PSC devices should be optimized. The JV characteristics and the performance parameters of PSC devices with different thicknesses of C70 as an ETL are shown in Fig. 3 and Table 1 respectively. A summary of the performance parameters reported in Table 1 is plotted in Fig. 4. As it can be seen in the table, a device without a C70 interface layer can only achieve a PCE of $0.56 \%$ with a VOC of $0.89 \mathrm{eV}$, JSC of 2.42 $\mathrm{mA} \mathrm{cm}-1$ and very low FF about $25.97 \%$. It is well-known that a PSC device without an electron transport and hole blocking layer exhibits severe charge recombination effects 
and shunts at the ITO/perovskite interface [3]. After an increase in the C70 thickness, no major change was observed in the open-circuit voltage (VOC) (Fig. 4), whereas the JSC first increased and then decreased. The optimized thickness of the C70 interface layer is about 10 $\mathrm{nm}$ (with the average PCE of about $11.52 \%$ ). If the thickness of the C70 layer is increased above $10 \mathrm{~nm}$, both the FF and JSC decreases.

Table 1. Performance parameters of the PSC devices with various thicknesses of the C70 layer as ETL. All the performance data were obtained from the average values of in total ten PSC devices for each thickness, where the error bars represent the standard deviation.

\begin{tabular}{l|cccc}
\hline $\begin{array}{l}\text { Thicknes } \\
\text { s of C70 }\end{array}$ & $\begin{array}{c}\text { VOC } \\
(\mathrm{V})\end{array}$ & $\begin{array}{c}\text { JSC } \\
\left(\mathrm{mA} / \mathrm{cm}^{2}\right)\end{array}$ & $\begin{array}{c}\text { FF } \\
(\%)\end{array}$ & $\begin{array}{c}\text { PCE } \\
(\%)\end{array}$ \\
\hline $0 \mathrm{~nm}$ & $0.89 \pm 0.04$ & $2.42 \pm 0.40$ & $25.97 \pm 3.15$ & $0.56 \pm 0.23$ \\
$7.5 \mathrm{~nm}$ & $0.95 \pm 0.03$ & $10.21 \pm 0.36$ & $53.82 \pm 3.19$ & $5.22 \pm 0.44$ \\
$10 \mathrm{~nm}$ & $1.03 \pm 0.01$ & $18.10 \pm 0.45$ & $61.82 \pm 1.63$ & $11.52 \pm 0.50$ \\
$20 \mathrm{~nm}$ & $1.02 \pm 0.01$ & $16.16 \pm 0.33$ & $62.60 \pm 1.44$ & $10.31 \pm 0.31$ \\
$30 \mathrm{~nm}$ & $1.04 \pm 0.04$ & $14.12 \pm 1.13$ & $63.27 \pm 4.07$ & $9.29 \pm 0.22$ \\
$40 \mathrm{~nm}$ & $1.04 \pm 0.05$ & $14.02 \pm 0.22$ & $58.71 \pm 3.34$ & $8.54 \pm 0.16$ \\
PC61BM & $0.95 \pm 0.04$ & $19.69 \pm 0.45$ & $57.43 \pm 2.20$ & $10.74 \pm 0.30$ \\
\hline
\end{tabular}
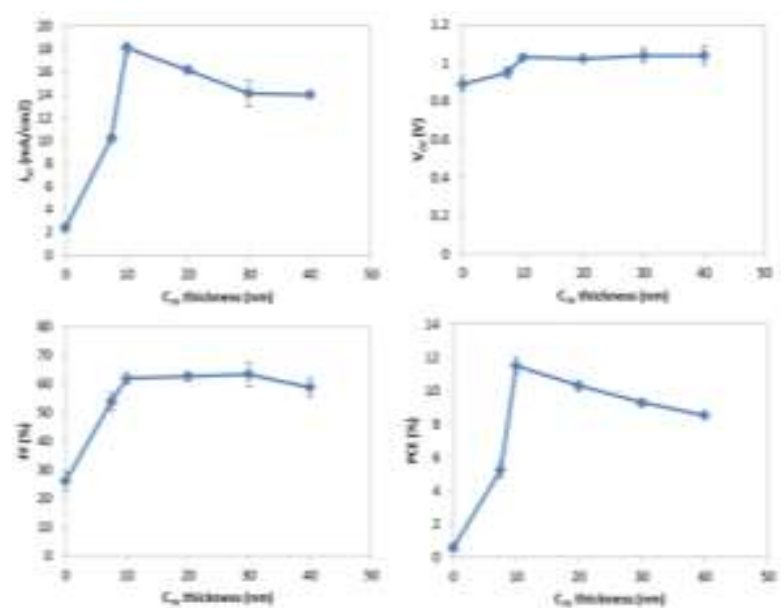

Fig. 4. The performance parameters of the PSC devices with various thicknesses of the $\mathrm{C} 70$ layer as ETL.

C70 has a relatively high absorption coefficient in the wavelength range of 350 $550 \mathrm{~nm}$, and the total absorption of course increases with film thickness in the processed layers [33]. This absorption potentially lowers the Jsc and thus PCE of perovskite devices with a conventional structure, as investigated in this work, due to the absorption loss in the active layer in this region. Thus the drop in Jsc beyond $10 \mathrm{~nm}$ thick $\mathrm{C} 70$ films can be explained partly by the drop in absorption of the perovskite layer at this wavelength range, while the increased series resistance in these devices, due to the thicker C70 layer, can explain the drop in FF and partly Jsc at increased thicknesses.

Steady state PL spectroscopy was measured to elucidate the photo-induced charge transfer and the charge recombination loss. Figure 5 shows the PL spectra of the ITO/perovskite and ITO/C70(10 nm)/perovskite films. The PL intensity of the ITO/C70 $(10 \mathrm{~nm}) /$ perovskite film is significantly weaker than that of the ITO/perovskite film. This suggests that the charge transfer at the C70 interface effectively occurred before carrier recombination takes place in the active layer, leading to a PL signal. Thus, the C70 layer significantly improved the electron extraction from the absorber layer, as also expected. According to Fig. 5, a C70 interface layer with a thickness of even a few nanometers can effectively block the holes and transport the electrons out of the active layer, allowing perovskite solar cells to use ultra-thin C70 films to achieve high performance.

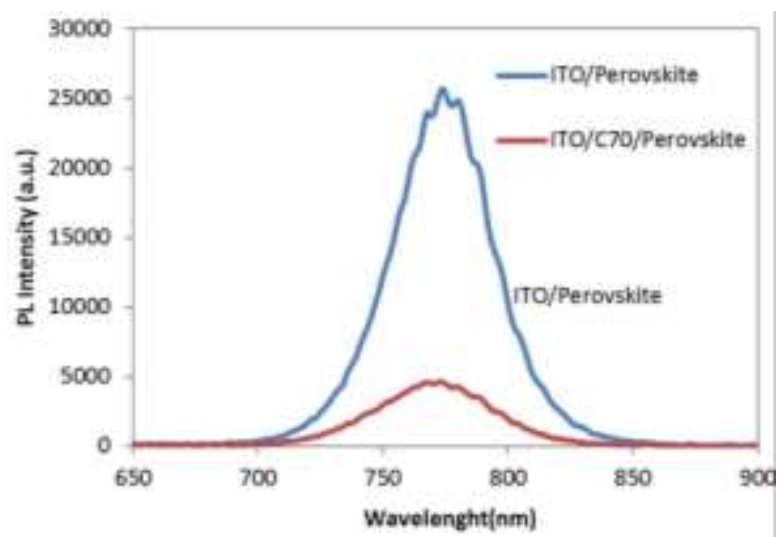

Fig. 5. The steady state photoluminescence (PL) measurements of the ITO/perovskite and ITO/C70(10nm)/perovskite films

\section{Conclusion}

In this study, planar perovskite solar cells with a conventional device structure that utilize C70 thin films as electron transport layers were developed. A high-quality $\mathrm{CH} 3 \mathrm{NH} 3 \mathrm{PbI} 3$ 
perovskite film was formed on C70-coated ITO substrates by the one-step solution method and through antisolvent treatment. Photoluminescence studies revealed the high electron-transporting and efficient holeblocking capabilities of the C70 layer. To achieve the best PSC performance, the C70 layer thickness was optimized to reduce the effects from ETL absorption and series resistance. According to the absorption spectrum of the C70 films, a C70 ETL thickness above $10 \mathrm{~nm}$ show relatively strong absorption in the wavelength range 350-550 $\mathrm{nm}$, and thus a reduction of the PSC performance due to drops in Jsc. At thicker C70 films, the FF also drops due to the increased series resistance while the Voc remains constant. The best PCE was $11.52 \% \pm$ 0.50 reported for a $10-\mathrm{nm}$-thick C70 layer used as an ETL in the device. As the results demonstrate, ultra-thin C70 films can effectively block holes and transport electrons in PSC devices, making them efficient electron selective contacts in such devices.

\section{ACKNOWLEDGEMENT}

A Behjat would like to thank the Iran National Science Foundation (INSF) for the financial support of this research (Research proposal No: 96003879).

\section{REFERENCE}

[1] S.D. Stranks, G.E. Eperon, G. Grancini, C. Menelaou, M.J.P. Alcocer, T. Leijtens, L.M. Herz, A. Petrozza, and H.J. Snaith, "Electron-Hole Diffusion Lengths Exceeding 1 Micrometer in an Organometal Trihalide Perovskite Absorber," Science, Vol. 342, pp. 341-344, 2013.

[2] P.-W. Liang, C.-C. Chueh, S.T. Williams, and A.K.Y. Jen, "Roles of Fullerene-Based Interlayers in Enhancing the Performance of Organometal Perovskite Thin-Film Solar Cells," Adv. Energy Mater. Vol. 5, pp. 1402321 (1-7), 2015.

[3] W. Ke, D. Zhao, C.R. Grice, A.J. Cimaroli, J. Ge, H. Tao, H. Lei, G. Fang, and Y. Yan, "Efficient planar perovskite solar cells using room-temperature vacuum-processed C60 electron selective layers," J. Mater. Chem. A, Vol. 3, pp. 17971-17976, 2015.

[4] Q. Lin, A. Armin, R.C.R. Nagiri, P.L. Burn, and P. Meredith, "Electro-optics of perovskite solar cells," Nat Photon, Vol. 9, pp. 106-112, 2015.

[5] C. Wang, X. Liu, C. Wang, Z. Xiao, C. Bi, Y. Shao, J. Huang, and Y. Gao, "Surface analytical investigation on organometal triiodide perovskite," J. Vac. Sci. Technol, Nanotechnology and Microelectronics: Materials, Processing, Measurement, and Phenomena, Vol. 33, pp. 032401 (1-7), 2015.

[6] S. Sun, T. Salim, N. Mathews, M. Duchamp, C. Boothroyd, G. Xing, T.C. Sum, and Y.M. Lam, "The origin of high efficiency in lowtemperature solution-processable bilayer organometal halide hybrid solar cells," Energy Environ. Sci. Vol. 7, pp. 399-407, 2014.

[7] H. Hu, D. Wang, Y. Zhou, J. Zhang, S. Lv, S. Pang, X. Chen, Z. Liu, N.P. Padture, and G. Cui, "Vapour-based processing of holeconductor-free $\quad \mathrm{CH} 3 \mathrm{NH} 3 \mathrm{PbI} 3$ perovskite/C60 fullerene planar solar cells," RSC Adv. Vol. 4, pp. 28964-28967, 2014.

[8] Z. Zhou, S. Pang, Z. Liu, H. Xu, and G. Cui, "Interface engineering for high-performance perovskite hybrid solar cells," J. Mater. Chem. A, Vol. 3, pp. 19205-19217, 2015.

[9] A. Kojima, K. Teshima, Y. Shirai, and T. Miyasaka, "Organometal Halide Perovskites as Visible-Light Sensitizers for Photovoltaic Cells," J. Am. Chem. Soc, Vol. 131, pp. 6050-6051, 2009.

[10]L. Meng, J. You, and Y. Yang, "Addressing the stability issue of perovskite solar cells for commercial applications," Nat. Commun, Vol. 9, pp. 5265 (1-4), 2018.

[11]C.-H. Chiang, Z.-L. Tseng, and C.-G. Wu, "Planar heterojunction perovskite/PC71BM solar cells with enhanced open-circuit voltage via a (2/1)-step spin-coating process," J. Mater. Chem. A, Vol. 2, pp. 15897-15903, 2014.

[12]D. Yang, X. Zhou, R. Yang, Z. Yang, W. $\mathrm{Yu}, \mathrm{X}$. Wang, C. Li, S. Liu, and R.P.H. Chang, "Surface optimization to eliminate hysteresis for record efficiency planar perovskite solar cells," Energy Environ. Sci. Vol. 9, pp. 3071-3078, 2016. 
[13]P. Docampo, J.M. Ball, M. Darwich, G.E. Eperon, and H.J. Snaith, "Efficient organometal trihalide perovskite planarheterojunction solar cells on flexible polymer substrates," Nat. Commun. Vol. 4, pp. 2761 (1-6), 2013.

[14] J.H. Heo, H.J. Han, D. Kim, T.K. Ahn, and S.H. Im, "Hysteresis-less inverted CH3NH3PbI3 planar perovskite hybrid solar cells with $18.1 \%$ power conversion efficiency," Energy Environ. Sci. Vol. 8, pp. 1602-1608, 2015.

[15]L. Meng, J. You, T.-F. Guo, and Y. Yang, "Recent Advances in the Inverted Planar Structure of Perovskite Solar Cells," Acc. Chem. Res. Vol. 49, pp. 155-165, 2016.

[16] L. Wang, W. Fu, Z. Gu, C. Fan, X. Yang, H. $\mathrm{Li}$, and $\mathrm{H}$. Chen, "Low temperature solution processed planar heterojunction perovskite solar cells with a CdSe nanocrystal as an electron transport/extraction layer," J. Mater. Chem. C, Vol. 2, pp. 9087-9090, 2014.

[17] O. Malinkiewicz, A. Yella, Y.H. Lee, G.M. Espallargas, M. Graetzel, M.K. Nazeeruddin, and H.J. Bolink, "Perovskite solar cells employing organic charge-transport layers," Nat. Photon. Vol. 8, pp. 128-132, 2014.

[18] Y. Shao, Z. Xiao, C. Bi, Y. Yuan, and J. Huang, "Origin and elimination of photocurrent hysteresis by fullerene passivation in $\mathrm{CH} 3 \mathrm{NH} 3 \mathrm{PbI} 3$ planar heterojunction solar cells," Nat. Commun. Vol. 5, pp. 5784 (1-7), 2014.

[19]F. Jafari, B.R. Patil, F. Mohtaram, A.L.F. Cauduro, H.-G. Rubahn, A. Behjat, and M. Madsen, "Inverted organic solar cells with non-clustering bathocuproine (BCP) cathode interlayers obtained by fullerene doping," Sci. Rep. Vol. 9, pp. 10422 (1-9), 2019.

[20] G. Sherafatipour, J. Benduhn, B.R. Patil, M. Ahmadpour, D. Spoltore, H.-G. Rubahn, K. Vandewal, and M. Madsen, "Degradation pathways in standard and inverted DBP-C70 based organic solar cells," Sci. Rep. Vol. 9, pp. 4024 (1-12), 2019.

[21]B.R. Patil, Y. Liu, T. Qamar, H.-G. Rubahn, and M. Madsen, "4P-NPD ultra-thin films as efficient exciton blocking layers in DBP/C 70 based organic solar cells," J. Phys. D, Vol. 50, pp. 385101 (1-9), 2017.
[22] M. Ahmadpour, Y. Liu, H. Rubahn, and M. Madsen, "Current Matching in Multifold DBP/C70 Organic Solar Cells With OpenCircuit Voltages of up to 6.44 V," IEEE J. Photovoltaics, Vol. 7, pp. 1319-1323, 2017.

[23] B.R. Patil, M. Ahmadpour, G. Sherafatipour, T. Qamar, A.F. Fernández, K. Zojer, H.-G. Rubahn, and M. Madsen, "Area dependent behavior of bathocuproine (BCP) as cathode interfacial layers in organic photovoltaic cells," Sci. Rep. Vol. 8, pp. 12608 (1-9), 2018.

[24] J.-Y. Jeng, Y.-F. Chiang, M.-H. Lee, S.-R. Peng, T.-F. Guo, P. Chen, and T.-C. Wen, "CH3NH3PbI3 Perovskite/Fullerene PlanarHeterojunction Hybrid Solar Cells," Adv. Mater. Vol. 25, pp. 3727-3732, 2013.

[25] R. Singhal, R. Vishnoi, M.K. Banerjee, R. Kaushik, K.V. Kamma, G.B.V.S. Lakshmi, A. Tripathi, and D.K. Avasthi, "Surface and structural studies of fullerene C70 under ion irradiation AU - Sharma, P," Surface Eng. Vol. 32, pp. 846-852, 2016.

[26] X. Lin, J. Seok, S. Yoon, T. Kim, B. Kim, and K. Kim, "Morphological investigation of P3HT/PCBM heterojunction and its effects on the performance of bilayer organic solar cells," Synth. Met. Vol. 196, pp. 145-150, 2014.

[27]M.V. Khenkin, K.M. Anoop, I. VisolyFisher, Y. Galagan, F. Di Giacomo, B.R. Patil, G. Sherafatipour, V. Turkovic, H.-G. Rubahn, M. Madsen, T. Merckx, G. Uytterhoeven, J.P.A. Bastos, T. Aernouts, F. Brunetti, M. Lira-Cantu, and E.A. Katz, "Reconsidering figures of merit for performance and stability of perovskite photovoltaics," Energy Environ. Sci. Vol. 11, pp. 739-743, 2018.

[28] M.V. Khenkin, K.M. Anoop, I. VisolyFisher, S. Kolusheva, Y. Galagan, F. Di Giacomo, O. Vukovic, B.R. Patil, G. Sherafatipour, V. Turkovic, H.-G. Rubahn, M. Madsen, A.V. Mazanik, and E.A. Katz, "Dynamics of Photoinduced Degradation of Perovskite Photovoltaics: From Reversible to Irreversible Processes," ACS Appl. Energy Mat. Vol. 1, pp. 799-806, 2018.

[29] X. Bao, Y. Wang, Q. Zhu, N. Wang, D. Zhu, J. Wang, A. Yang, and R. Yang, "Efficient planar perovskite solar cells with large fill 
factor and excellent stability," J. Power Sources, Vol. 297, pp. 53-58, 2015.

[30] J. Xiong, B. Yang, R. Wu, C. Cao, Y. Huang, C. Liu, Z. Hu, H. Huang, Y. Gao, and J. Yang, "Efficient and non-hysteresis CH3NH3PbI3/PCBM planar heterojunction solar cells," Org. Electron. Vol. 24, pp. 106112, 2015.

[31]L. Huang, Z. Hu, J. Xu, K. Zhang, J. Zhang, and Y. Zhu, "Multi-step slow annealing perovskite films for high performance planar perovskite solar cells," Sol. Energy Mater. Sol. Cells, Vol. 141, pp. 377-382, 2015.

[32] N. Ahn, D.-Y. Son, I.-H. Jang, S.M. Kang, M. Choi, and N.-G. Park, "Highly Reproducible Perovskite Solar Cells with Average Efficiency of $18.3 \%$ and Best Efficiency of $19.7 \%$ Fabricated via Lewis Base Adduct of Lead(II) Iodide," J. Am. Chem. Soc. Vol. 137, pp. 8696-8699, 2015.

[33] X. Xi, W. Li, J. Wu, J. Ji, Z. Shi, and G. Li, "A comparative study on the performances of small molecule organic solar cells based on $\mathrm{CuPc} / \mathrm{C} 60$ and $\mathrm{CuPc} / \mathrm{C} 70$," Sol. Energy Mater. Sol. Cells, Vol. 94, pp. 2435-2441, 2010.

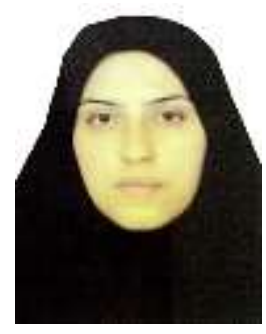

Fatemeh Jafari Nodoushan received her BSc in nuclear Physics in 2006 from Isfahan University of Technology and M.Sc. degrees in atomic and molecular Physics from Yazd University in 2012. Her current research interests in $\mathrm{PhD}$ include: Fabrication and optimization of perovskite solar cells based on different organic /inorganic electron transport layers.

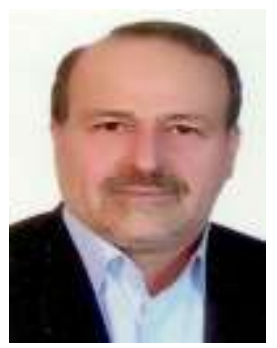

Abbas Behjat is the Professor of Physics, at Yazd University, Iran. He obtained his Ph.D. in x-ray lasers from the Essex University (UK) in 1996. Currently, he is group leader in the Photonics Research Group (PRG), Engineering Research Center, at Yazd University. Since 2007, he has been mainly involved in nanostructure-based optical devices including light emitting diodes, quantum dots and dye sensitized solar cells and perovskite and also polymer bulk heterojunction solar cells. Currently he is PI on Iran National Science Foundation (INSF) research silk-road joined project on highly efficient and stable perovskite solar cells based on interface engineering and charge transport investigations.

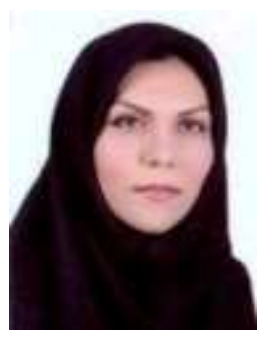

Naeime Torabi received her M.Sc. degree in Photonics from the Shahid Beheshti University (Tehran), Iran in 2009. She obtained her Ph.D. in third generation solar cells with focuses on organic tandem solar cells, at Yazd University, Iran in 2015. As a member of Photonics Research Group at Yazd University she is now working on new generation solar cells such as polymer and Perovskite solar cells. Currently she is co-PI on Iran National Science Foundation (INSF) research silk-road joined project on highly efficient and stable perovskite solar cells based on interface engineering and charge transport investigations. 


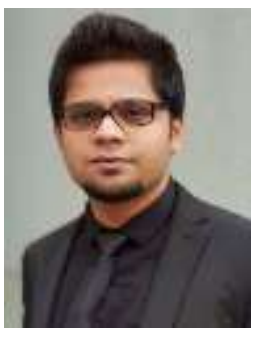

Bhushan Ramesh Patil received his Ph.D. in Engineering Science from the University of Southern Denmark in 2017. He received his $\mathrm{BE}$ in Electronics and Telecommunications in 2010 from the University of Mumbai, India and M.Sc. degree in Micro and Nano Systems from Technische Universitaet Chemnitz, Germany in 2014. He is working as a postdoctoral researcher at the University of Southern Denmark and his research interests include: Sheet-to-sheet/Roll-to-roll fabrication of Organic solar cells as well as interfacial layers and semi-transparent electrodes for large area flexible Organic Solar Cells.

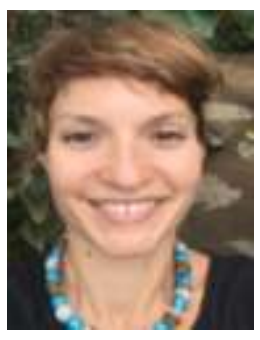

Vida Turkovic obtained her Dr. rer. nat in 2014 from the Ilmenau University of Technology under the supervision of Prof. Dr. Gerhard Gobsch. In 2014 she joined the OPV group at Mads Clausen Institute of University of Southern Denmark as a postdoctoral researcher. In 2017 she was appointed assistant professor, with the focus on degradation and additive-assisted stabilization of organic solar cells. Her international research stays include Uppsala University, University of Colorado Boulder / NREL, and Russian Academy of Sciences Chernogolovka. She authored numerous publications in highimpact journals such as Nature Energy, Energy \& Environmental Science, Advanced Energy Materials, ACS Applied Materials \& Interfaces, and one chapter in a scientific book, as well as edited the World Scientific
Reference of Hybrid Materials - Vol. 2. For her research, she has been awarded the postdoctoral fellowship by the Independent Research Fund Denmark, EU COST action MP1307, I-CAM fellowship, as well as the Thuringian State Graduate stipend, and she is currently co-PI on a Villum Foundation research project on mechanical stabilization of organic solar cells. In 2019 she received the UNESCO-L'Oréal For Women in Science award.

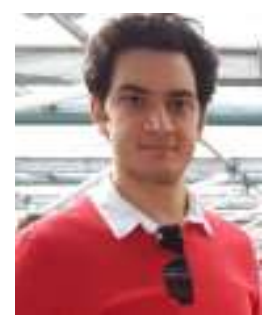

Mehrad Ahmadpoor received his Ph.D. degrees in "Metal-Oxide based interlayers for organic and perovskite photovoltaics" from University of Southern (SDU) Denmark in 2017. He is working as Post Doc. researcher in SDU.

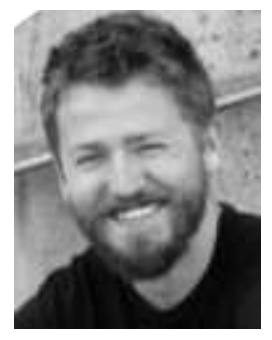

Morten Madsen is a professor wsr at the University of Southern Denmark, SDU NanoSYD. His main research focus on electronic and optoelectronic devices based on semiconducting thin-films. Conducted a postdoc fellowship at Prof. Ali Javey lab, UC Berkeley, and started in 2011 the OPV group at SDU NanoSYD. Is also heading the SDU Roll-to-Roll facility that focus on complete upscaling of organic photovoltaics. Holds around 60 peer-reviewed publications on these topics, including publications in Nature, Nature Energy, Energy \& Environ. Sci., Nano Letters, Advanced Materials, etc. Is an editor 
on the book 'Devices from Hybrid and Organic Materials' part of the 'World Scientific Reference of Hybrid Materials' 2019 book series. Coordinator and PI of the FP7 ITN Marie Curie project THINFACE, which stands out as a very successful Marie Curie ITN training network with a high number of peer-reviewed publications per early stage researcher. Committee member of the $\mathrm{PhD}$ school board at the TEK faculty, SDU, and currently PI on the EU Interreg 5A project RollFlex, focused on roll-to-roll (R2R) printing of organic solar cells, and on several national research projects (DFF FTP and Villum Foundation). 
THIS PAGE IS INTENTIONALLY LEFT BLANK. 